\title{
"Delivering as one" UN reform process to improve health partnerships and coordination: old challenges and encouraging lessons from Pakistan
}

\author{
K.M. Bile, ${ }^{7}$ K.A. Lashari $^{2}$ and A.F. Shadoul ${ }^{1}$
}

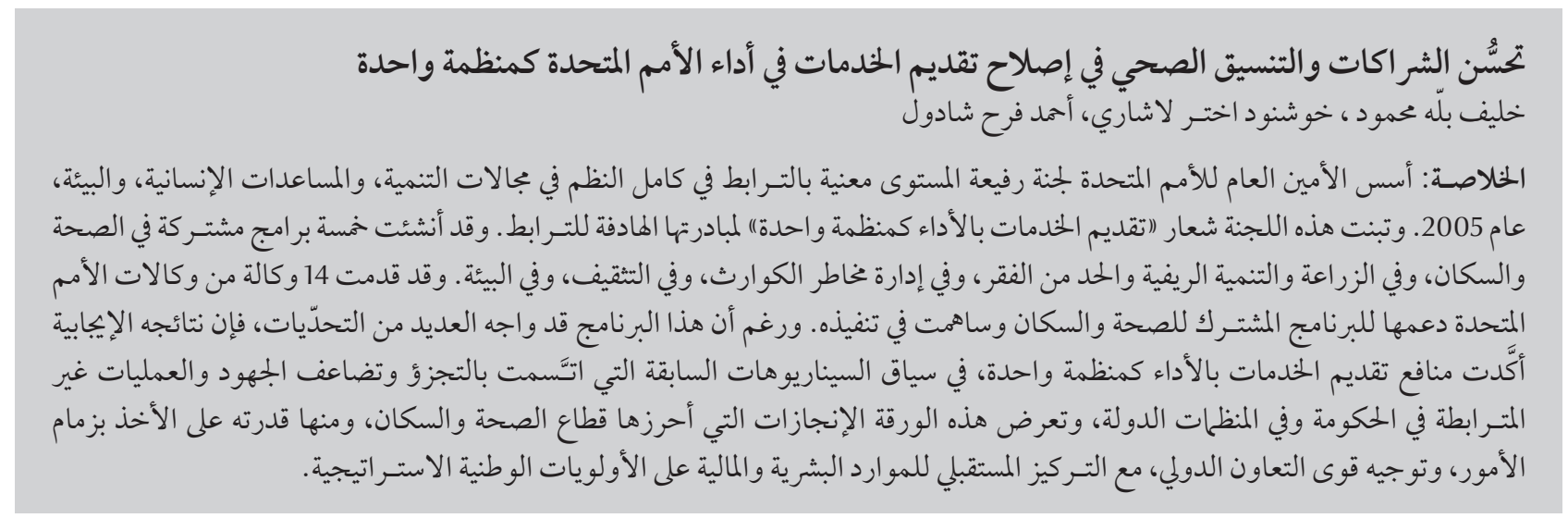

ABSTRACT The UN Secretary-General constituted a high-level panel on system-wide coherence in 2005 within the areas of development, humanitarian assistance and the environment. The panel adopted "Delivering as One" as a slogan for its coherence initiative. Pakistan was among eight pilot countries implementing this reform initiative. Five joint programmes were developed, on health and population; agriculture, rural development and poverty reduction; disaster risk management; education; and environment. Fourteen UN agencies supported the health and population joint programme and participated in its implementation. Although confronted by many challenges, the positive results of the joint programmes confirmed the advantage of Delivering as One over the past scenarios of fragmentation, duplication and incoherent government and UN strategic operations. The paper shares the accomplishments of the health and population sector including its ability to harness the power of intersectoral collaboration and prospectively concentrate human and financial resources around the strategic national priorities.

\footnotetext{
"Unis dans l'action », processus de réforme des Nations Unies pour améliorer les partenariats pour la santé et leur coordination : anciens défis et enseignements encourageants au Pakistan

RÉSUMÉ En 2005, le Secrétaire général des Nations Unies a formé un Groupe de haut niveau sur la cohérence de l'action du système des Nations Unies dans les domaines du développement, de l'aide humanitaire et de la protection de l'environnement. Celui-ci a choisi le slogan « Unis dans l'action ». Le Pakistan faisait parti des huit pays pilotes choisis pour mettre en œuvre cette réforme. Cinq programmes conjoints ont été conçus dans les domaines suivants : santé et population; agriculture, développement rural et réduction de la pauvreté ; gestion des risques de catastrophe ; éducation; et environnement. Quatorze agences de l'ONU ont soutenu le programme conjoint pour la santé et la population et ont participé à sa mise en œuvre. Malgré de nombreuses difficultés, les résultats positifs des programmes conjoints ont confirmé la supériorité de l'initiative « Unis dans l'action » par rapport aux scénarios précédents caractérisés par la fragmentation, la redondance et l'incohérence des opérations stratégiques gouvernementales et onusiennes. Cet article décrit les réalisations du secteur santé et population, notamment sa capacité à exploiter la puissance de la collaboration intersectorielle, et au préalable, à concentrer les ressources humaines et financières sur les priorités stratégiques nationales.
} 


\section{Introduction}

The "Millennium Declaration" of 2000 provided a global vision offering greater maternal, infant and child survival, better education for children, equal opportunities for women, a healthier environment and national and international partnerships supporting the pursuit of a sustainable development framework for action [1]. However, this commitment was undermined by a lack of focus on results, thereby failing the aspirations of many developing nations, especially the vulnerable and the poor [2-4]. Responding to this concern, the United Nations (UN) SecretaryGeneral constituted a high-level panel on system-wide coherence in 2005 within the areas of development, humanitarian assistance and the environment [5]. The panel reiterated the UN's support for the Millennium Development Goals, sustainable development, rapid response to humanitarian disasters and for protecting the environment [4]. The panel outlined the fragmented nature of UN work, policy incoherence, duplication and poor implementation. To overcome these challenges, it emphasized "Delivering as One" as the central theme of its recommendations and called for greater UN coherence, while linking the UN funding process to performance and results. The panel recommended the pursuit of one strategy and one set of goals, while establishing one UN presence at the country level, with one leader, one programme, one budget and where appropriate one office [4].

To promote the Delivering as One initiative, eight governments, including Pakistan's, were entrusted to pilot implementation and generate lessons for future potential replication consistent with the principle of national ownership and "no one size fits all", with prominent UN support [6,7]. Since 2007, Pakistan has introduced key reform elements that synchronize joint efforts and strengthen coordination, strategic planning, monitoring and evaluation [8].

To accommodate this vision, the United Nations Development Assistance Framework (UNDAF) of 2003-08 was extended till the end of 2010, reviewed and aligned with national development goals, expressed in Pakistan's medium-term development framework, poverty reduction strategy paper, UN Millennium Development Goals and Vision 2030. Nineteen UN agencies working in Pakistan endorsed the Delivering as One arrangement for 2009-10 and translated it into five thematic programmes: health and population; agriculture, rural development and poverty reduction; disaster risk management; education; and environment. These programmes were jointly formulated with federal and provincial governments and shared with civil society organizations and other development partners [19-12]. They are currently being implemented through a range of 21 joint programme components.

The Delivering as One initiative aims to attain the Millennium Development Goals with a focus on the poor and disadvantaged; harness the expertise of different UN agencies for effective implementation and coherence with sectoral development plans; promote equity, universal access to essential social services; and enhance intersectoral collaboration $[4,8]$. This study aims to describe Pakistan's Delivering as One implementation process and the experience gained, and share the accomplishments of the health and population sector and its ability to harness intersectoral collaboration and focus the scope of future action on the set national strategic priorities.

\section{Methods}

The information in this paper was the product of the authors' direct participatory insight in the Delivering as One process and a desk review of the experience gained since the Delivering as One initiative began in Pakistan. Focused interactions with health sector policymakers, supported by a survey of UN heads of agencies and the Resident Coordinator of their perception of the work of the Delivering as One initiative were carried out. The reports of different $\mathrm{UN}$ visiting missions, proceedings of joint programme consultations and UN intercountry, regional and global policy, strategic and programmatic deliberations on Delivering as One were also scrutinized.

\section{Results}

\section{The Delivering as One initiative}

InPakistan, thehigh-level panel deliberations and established guiding principles [4] were endorsed in their entirety. The Delivering as One initiative envisioned a UN resident coordinator system that include a country team led by a resident coordinator as the single leader but jointly assisting in the planning, implementation, monitoring and evaluation of the UN reform process relevant to the five joint programmes (Table 1) that complement and support nationally defined sectoral priorities. These joint programmes were developed through UN and government consultations examining the current progress in each sector, and the inherent strengths, weaknesses, opportunities and threats. A UN capacity assessment survey was also carried out to build a broad based consensus on each agency's comparative advantages in support to these joint programmes.

\section{Translating the Delivering as One initiative into action}

To promote the Delivering as One joint efforts, the UN and government partners laid down the following principles to enhance the development process towards Millenium Development Goals: 


\begin{tabular}{|c|c|}
\hline $\begin{array}{l}\text { Joint programmes (number of } \\
\text { participating agencies) }\end{array}$ & Joint programme components (JPC) \\
\hline $\begin{array}{l}\text { Agriculture, rural } \\
\text { developmentand poverty } \\
\text { reduction (11) }\end{array}$ & $\begin{array}{l}\text { - Pro-poor sustainable agriculture and rural development } \\
\text { - Decent employment and poverty alleviation } \\
\text { - Empowerment, mobilization and protection of poor and vulnerable groups } \\
\text { - Millennium Development Goals-driven pro-poor policy framework }\end{array}$ \\
\hline Disaster risk management (12) & $\begin{array}{l}\text { Disaster risk management: strengthened policies, norms, institutional capacities with } \\
\text { emphasis on preparedness and response; integrated multisectoral knowledge, information } \\
\text { and communication system and reaching out to the grass roots; human resource } \\
\text { development at all levels }\end{array}$ \\
\hline Education (9) & $\begin{array}{l}\text { - Preschool and elementary education } \\
\text { - Adult literacy and informal basic education } \\
\text { - Strengthening the education system } \\
\text { - Secondary education with a focus on technical and vocational education and life skills }\end{array}$ \\
\hline Environment (11) & $\begin{array}{l}\text { - Strengthened and operational institutional mechanisms for integrated environmental } \\
\text { management } \\
\text { - Integrated programme on access to safe water and sanitation } \\
\text { - Integrated natural resources management in demonstration regions } \\
\text { - Sustainable urbanization } \\
\text { - Support for green industries, waste management, energy and Jobs }\end{array}$ \\
\hline Health and population (14) & $\begin{array}{l}\text { - Maternal, neonatal, and child health and family planning/reproductive health in the context } \\
\text { - } \text { Communicable disease control } \\
\text { - Nutrition and health promotion } \\
\text { - Health system development } \\
\text { - HIV and AIDS } \\
\text { - Population and census }\end{array}$ \\
\hline
\end{tabular}

- Align the delivery of UN development support with key sectoral priorities and apply national systems and procedures for their implementation while engaging in "upstream" policy and programme dialogue and promoting equity and capacity development

- Promote the "managing for results" concept, by introducing performance-based criteria and effective resource targeting and allocation, while advancing ownership, coherence, reduced transaction costs and flexibility when responding to national development challenges.

- Use existing UN funding mechanisms of core and voluntary contributions effectively, as well as the supplementary expanded financing window, recognizing the need for multi-year funding predictability.

- Foster harmonization by working together and promoting the division of roles in line with the agencies' mandates and respective comparative advantages and integrate best practices in all joint programme components and assess the progress of implementation, using jointly defined programme indicators and targets, and synchronized monitoring, evaluation and audit systems.

- Endorse the stipulated UN dual accountability management of the UN country team in the Delivering as One framework, mandating unity of purpose under the resident coordinator system, while concurrently rendering UN country team members answerable to their agencies' respective organizational work.

- Assess the progress of mainstreaming the cross-cutting issues of gender, human rights, civil society organizations and refugees in view of their strong relevance to the successful implementation of joint programmes.
- Assist national partners on emergency preparedness and response with focus on vulnerability and disaster risk reduction and apply best practices for planning and programme implementation.

- Revisit the existing interagency overlaps, duplications and operational gaps, and identify solutions to rectify these in the course of planning and implementation of the Delivering as One interventions.

\section{Formulating joint programmes}

The government-driven joint programming led to the formulation of five joint programmes and a subset of 21 joint programme components ( $\mathrm{Ta}$ ble 1). These joint programmes were translated into common operational work plans, involving two or more UN agencies along with their government counterparts. UN participation in one joint programme ranged from nine to 
fourteen agencies, reflecting the existing synergies and complementarities between different $\mathrm{UN}$ organizations.

\section{Governance mechanisms for joint programming}

The following mechanisms were established for coordinating and managing the Delivering as One reform process.

\section{Government and UN joint mecha- nisms}

The high-level committee and the joint programme steering committee are key government and UN joint mechanisms established in support of the Delivering as One process.

The high-level committee is chaired by the prime minister or his/her representative bringing together federal and provincial government line departments and $\mathrm{UN}$ and donor members. Its job is to oversee the Delivering as One reform process, monitor its progress and provide necessary institutional support. The high-level panel is assisted by an executive committee entrusted to support the implementation of the joint programmes and facilitate their resource allocation processes. The executive committee comprise the secretary of the economic affairs division, the $\mathrm{UN}$ resident coordinator and a donor representative.

Five joint programme steering committees guide the planning, resource allocation, implementation and the management of joint programmes. Each joint programme steering committee is co-chaired by a government representative at the level of federal secretary (or equivalent) and the representative of a lead UN agency, with membership from all UN and government participating agencies while civil society organizations and donors can participate as observers. Each of the 21 joint programme components is managed by a joint programme component task force that reports to the joint programme steering committee and is accountable for the joint programme component formulation, planning, implementation, monitoring and coordination. The participation and co-chairing of the joint programme component task force is structurally identical to the joint programme steering committee, but directed by senior government and UN professionals who are specialists in their respective fields.

\section{UN joint mechanisms at the country level}

At country level, UN development assistance is coordinated by the resident coordinator system bringing together all resident and non-resident UN organizations engaged in the country's development support.

The resident coordinator leads the UN country team, coordinates the Delivering as One initiative and facilitates its implementation, while upholding the UN-stipulated code of conduct and maintaining regular communication with the government, $\mathrm{UN}$ country team and the higher tiers of the UN system.

The UN country team led by the resident coordinator consists of all heads of UN agencies, funds and programmes and represent the interagency coordination and decision-making body. The UN country team provides support to the different joint programmes and is responsible for achieving the Delivering as One results. To harmonize the UN technical support for this initiative, a thematic working group was created for each joint programme, co-chaired by a lead substantive agency, permanently assuming this role, and by a second participating agency rotating on a yearly basis. An interagency working group was similarly established to coordinate and enhance the UN in-house active participation in the joint programme component task force. To harmonize and simplify business practices, an operational management team was established. The operational management team identified a common human resourcemanagementcentre,acommon procurement facility and standardized web-based material. A communication group was also launched to assist the Delivering as One implementation.

\section{Headquarters and regional UN agen- cies' support mechanisms}

To promote UN system-wide coherence and the Delivering as One initiative, the following supportive structures were established.

The chief executive board is the highest UN forum that brings together the executive heads of all UN agencies under the leadership of the UN Secretary-General, mandated to promote coordination and cooperation on a range of substantive and managerial issues facing the UN system organizations. The chief executive board is supported by three high-level committees: the United Nations Development Group (UNDG) consisting of $32 \mathrm{UN}$ funds, programmes, agencies, departmentsand offices. UND G guides the management of resident coordinators, the regional management teams and promotes coherent oversight, capacity-building and coordination of UN development operations at country level including the implementation of the triennial comprehensive policy review of the UN System. The Development Operations Coordination Office assists UNDG by extending its technical and financial support to the UN resident coordinator system, conducting oversight of the multi-donor trust fund, coordinating the regional management teams' and UN country teams' support to the Delivering as One initiative. The High-level Committee on Management works on system-wide administrative and management issues, and a the High-level Committee on Programmes addresses the global programmatic issues and provides strategic guidance, leadership and coherent technical support to the $\mathrm{UN}$ agencies' regional directors team, resident coordinators and UN country teams. In addition to these institutional 
arrangements, each UN organization has established a focal desk in support of the Delivering as One initiative at their regional offices and headquarters. In the World Health Organization (WHO), the Director-General and regional directors have recognized Delivering as One since its inception as the sine qua non strategic policy choice of the Organization and have drawn the attention of WHO Member States on the potential of linking health to the mainstream of the Delivering as One development process.

The Regional Directors' team provides strategic leadership and policy guidance to the resident coordinator system and supports the UN country team in promoting coherence of the UN work in the country, oversees performance and assumes a problem-solving role in difficult situations to consolidate interagency collaboration.

The Delivering as One joint programmes are primarily financed by the assessed and voluntary contributions provided to UN organizations. Funds are also obtained by the Delivering as One incremental Development Operations Coordination Office managing the expanded funding window of the multi-donor trust fund and other contributions. Considering all sources of funding, the projected budgetary outlay of the five joint programmes was estimated at US\$ 396 million per year, whereas the proportional allocations for agriculture, rural development and poverty reduction; disaster risk management; education; environment; and health and population were $21.3 \%$, $17.7 \%, 22.0 \%, 6.7 \%$ and $32.3 \%$, respectively. The collective resource gap of the five joint programmes was $80.4 \%$ at the planning outset, indicating the prevailing challenges for resource mobilization.

The health and population joint programme was designed in close collaboration with federal ministries of health and population welfare along with their provincial line departments, civil society organizations and international partners. Apart from the population census joint programme component, the remaining five health and population joint programme components address key public health priorities fully aligned with the poverty reduction strategy paper and Millennium Development Goals strategies and targets.

Table 2 shows the UN agencies participating in the health and population joint programme.

Table 3 shows the six formulated joint programme components of

\begin{tabular}{ll}
\hline Table 2 Participating UN agencies in the health and population joint programme \\
\hline Abbreviated name & Full name \\
ILO & International Labour Organization \\
IOM & International Organization for Migration \\
UNAIDS & Joint United Nations Programme on HIV/AIDS \\
UNDP & United Nations Development Programme \\
UNESCO & United Nations Educational, Scientific and Cultural \\
UNFPA & Organization \\
UNICEF & United Nations Population Fund \\
UN-HABITAT & United Nations Children's Fund \\
UNHCR & United Nations Human Settlements Programme \\
UNIFEM & Office of the United Nations High Commissioner for \\
UNODC & Refugees \\
WFP & United Nations Development Fund for Women \\
WHO & United Nations Office on Drugs and Crime \\
\hline
\end{tabular}

the health and population joint programme, the participating UN agencies and their envisaged outcomes. Agencies' participation in the different joint programme components reflected the scope of their technical engagement mandates and operational capacities on the ground.

As a prototype of the joint programme components' implementation paradigm, the field implementation of the joint programme component for maternal, neonatal and child health is shown in Table 4. This targets ten districts of Sindh province, with technical roles of each participating UN agency explicitly identified, while jointly assisting and monitoring implementation to consolidate the Delivering as One principle. Figure 1 illustrates the existing nexus between the health and population joint programme and other joint programmes whose operational roles contribute to the social determinants of health. The dependence of health development outcomes on the performance scope of other joint programmes is illustrated, legitimizing the role of the health and population joint programme participating agencies in strengthening and expanding the inter-joint programme synergies. In planning the health and population joint programme and related joint programme components, the evolving opportunities for intersectoral action were addressed, recognizing the effect social determinants of health interventions exert on health and population outcomes. The latter is exemplified by the incremental gains that would accrue to the health sector by improving the quality, accessibility and length of female education; improving coverage of household level safe drinking water and sanitation, creating means of livelihood, availing better nutrition and disposal of hazardous solid waste, all concerns that have a major bearing on health. 


\section{Table 3 The six health and population joint programme components, their envisaged outcomes and the UN agencies participating in their implementation \\ Health and population joint programme components \\ Joint programme component 1: maternal, neonatal and child health including reproductive health/family planning \\ Outcome 1: (UNICEF, WHO, UNFPA) Infant and maternal mortalities reduced and integrated maternal, neonatal and child health, including reproductive health family planning and services, implemented \\ Outcome 2: (UNICEF, WHO, UNFPA) Community demand and participation and intersectoral linkages for maternal, neonatal, and child health and reproductive health/family planning services are improved \\ Outcome3: (UNICEF, WHO, UNFPA, Nutrition status especially of infants, young children and child-bearing women is WFP) improved}

\section{Joint programme component 2: communicable diseases control}

Outcome 1: (WHO, UNICEF, UNHCR) Morbidity and mortality due to vaccine-preventable diseases reduced; polio eradication and measles elimination programmes have achieved their targets

Outcome 2: (WHO, UNHCR, WFP, Tuberculosis and other priority endemic communicable diseases controlled IOM)

Outcome 3: (WHO, UNICEF, UNHCR, Malaria incidence reduced and an integrated national programme for zoonotic and other $\mathrm{FAO})$

Outcome 4: (WHO, UNICEF) vector-borne diseases launched to mitigate burden

Outcome 5: (WHO, UNICEF)

Hepatitis B and C are prevented and disease burden controlled

National integrated communicable disease surveillance and outbreak response system made operational

\section{Joint programme component 3: health promotion and nutrition}

Outcome 1: (WHO, UNICEF, WFP, UNFPA, UNESCO)

Outcome 2: (UNICEF,WHO, WFP, UNHCR)

Knowledge and practices for health promotion (attitudes, behaviour/lifestyle) and avoidance of health risks and disease prevention are improved (including school health) Nutritional status of the population is improved

Joint programme component 4: health system development

Outcome 1: (WHO, UNHCR, UNICEF, An effective system of human resource development for health and population is adopted ILO, UNIFEM, UNFPA)

Outcome 2: (ILO, WHO, UNICEF, An equitable, effective health and population financing system is in place UNFPA)

Outcome 3: (WHO, UNHCR, UNICEF, Policy and management decisions by federal, provincial and district governments UNFPA) on health and population issues are evidence-based using research and improved information system

Outcome 4: (WHO, UNHCR, UNICEF, Effective systems for management of medical technologies are used UNFPA)

Outcome 5: (WHO, UNDP, ILO,

UNICEF, UNFPA)

Quality assurance and regulation systems of public and private providers of essential health services delivery are fully atained

Outcome 6: (UNDP, UNFPA, UNHCR, Governance in health and population systems is significantly improved UNICEF, WHO)

Outcome 1: (UNODC, UNAIDS, UNFPA, UNICEF, ILO, UNESCO, $\mathrm{WHO}$ )

Outcome 2: (UNDP, UNAIDS, ILO, UNESCO, UNICEF, IOM)

Outcome 3: (UNICEF, WHO, WFP, ILO, UNAIDS, UNIFEM, UNFPA, UNDP, UNODC, UNHCR)

Outcome 1: (ILO, UNDP, UNESCO, UNFPA, UNICEF, UN-HABITAT, UNIFEM)

\section{Joint programme component 5: HIV and AIDS}

HIV transmission is contained in the vulnerable groups by contributing $10 \%$ towards national strategic targets

Multisectoral opinion leaders take up and integrate HIV, AIDS issues in their programme portfolios and policies (representatives from government, religious leaders, media, parliamentarians, employers, workers, educators and agriculture extension workers)

, Accessibility and use of quality treatment by all people living with HIV is improved (focus: women and children). Support for all persons infected and affected by HIV is increased through strengthening civil society organizations working with people living with HIV (focus: women and children) (support: social, spiritual, and economic)

\section{Joint programme component 6: population census}

Pakistan census organization to adopt modern technology and approaches to conduct accurate housing and population census 


\section{Discussion}

The Delivering as One initiative has introduced coherence, effectiveness, accountability and management for results, with UN technical assistance inextricably aligned with national priorities [4]. The alignment of the joint programmes with national priorities required the channelling of $80 \%$ of UN agencies' funding to Delivering as One with coordinated and shared planning, implementation and monitoring, recognizing the UN agencies' distinct mandates and capacities [8].

WHO technical collaboration with the government used to be coordinated and designed through a biennial joint programming review aimed at assisting national core strategic health priorities. The latter focused on policy and health system development, control of communicable and noncommunicable diseases, improving the health of women and children, addressing social determinants of health, emergency preparedness and response and enhancing partnerships, all being priority subject areas that have become integral components of the health and population joint programme [13]. WHO-assisted interventions included a community based, integrated and health centred basic development needs initiative that produced capacity for intersectoral collaboration [14]. Moreover, the appropriateness of $\mathrm{WHO}$ business practices of resource allocation and releases to support national health interventions through the current mechanism of direct financial contribution has enabled the Organization to use the national management procedures with ease. These programmatic and managerial experiencessubstantiate the feasibility of the Delivering as One reform process, its capacity to assemble a wider participatory action and generate greater aspirations to produce the anticipated results [15]. This strategic and programmatic experience has enabled WHO to align over $90 \%$ of its entire budgetary outlay of assessed and voluntary contributions with the Delivering as One-prescribed health and population joint programme components. Moreover, the Delivering as One implementation process has demonstrated the essential WHO coordination role, within the thematic working group and joint programme steering committee governing bodies, requiring the Organization to promote more partnerships for the health sector

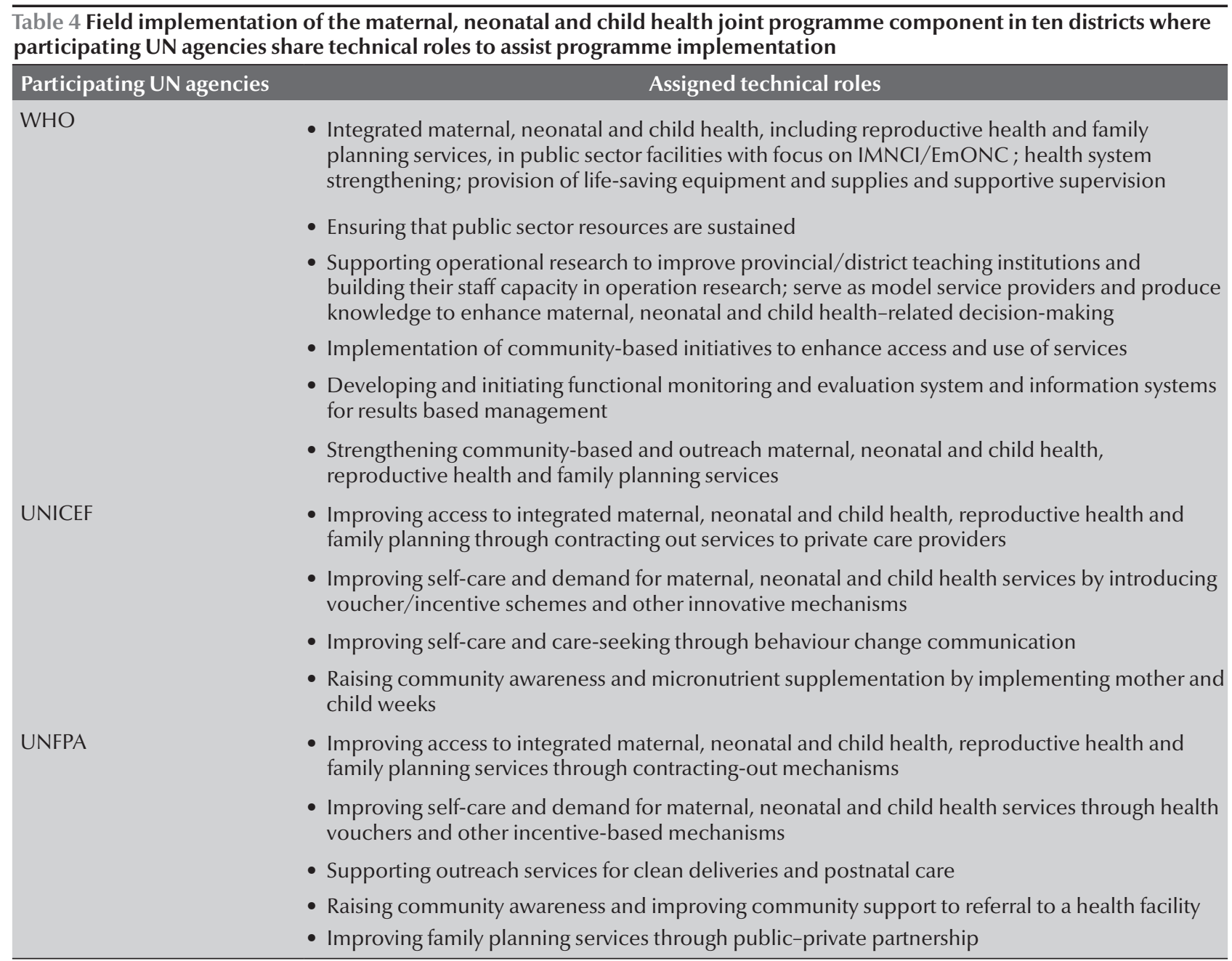




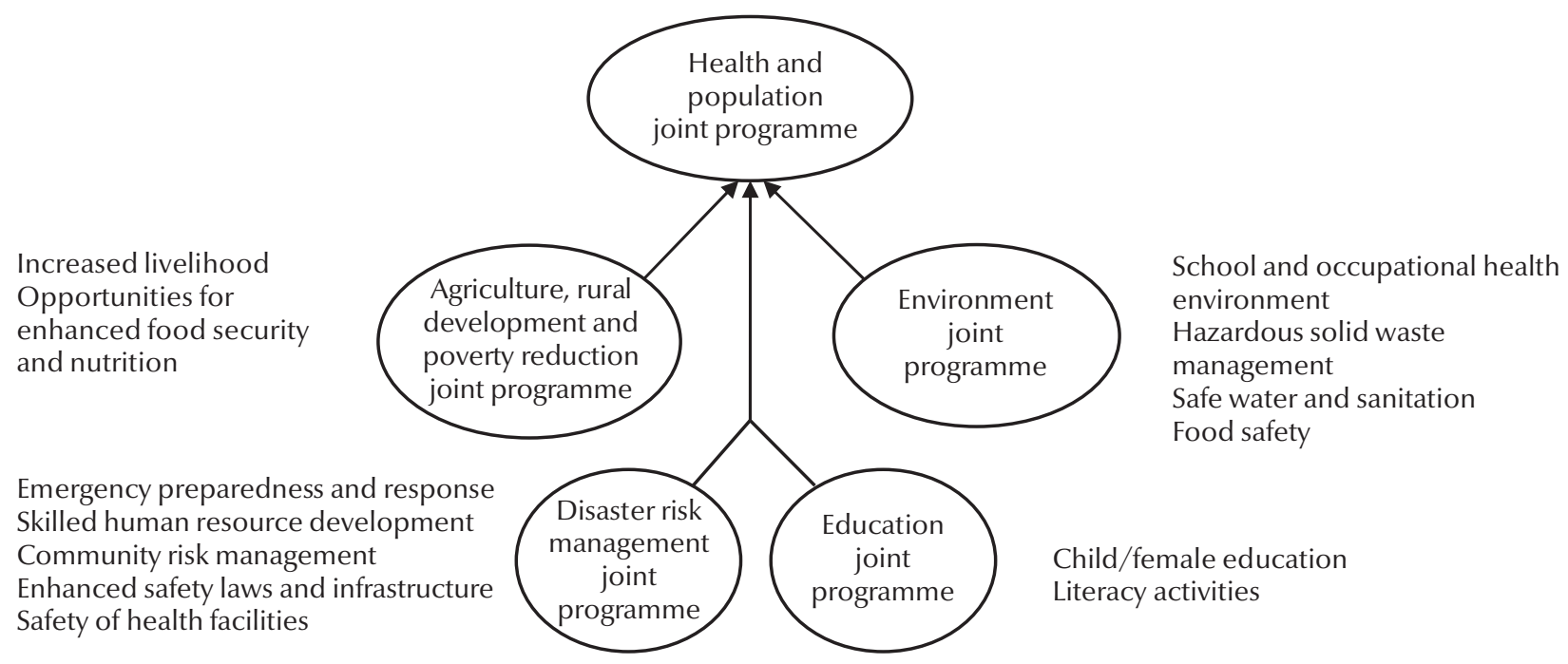

Figure 1 The positive nexus that links the health and population joint programme with the other four joint programmes enhancing collaborative synergies on the social determinants of health

to facilitate further cohesion and focus on results.

The health and population joint programme components were immediately launched with the active involvement of participating UN and government partners. A case in point was the maternal, neonatal, and child health joint programme component implemented in ten districts of Sindh province, and executed by the provincial health department, with assistance from the Ministry of Health and the three participating UN agencies. Similar arrangements were made for routine immunization and polio eradication, control of HIV/AIDS, health system strengthening, school health and other programmes. Through this process the participating UN agencies coordinated their technical and operational roles, benefiting from the capacity assessment survey and strengths, weaknesses, opportunities and threats analysis carried out at the outset of the Delivering as One process.

The Delivering as One initiative required partners to end fragmentation, competition and operational verticality that have long afflicted both government and UN operations, and focus instead on national priorities and results-based action. This new paradigm promoted the role of civil society organizations and grassroots communities as partners and stakeholders rather than contractors and beneficiaries, respectively [16]. However, to maintain the effective course of this development process, the alignment spirit has to transcend the UN and government partners and influence all stakeholders including international financial institutions and bilateral development partners who need to fulfil their global commitment to international financial cooperation [17].

Within the health and population domain, the Delivering as One initiative was successful in bringing together the Ministry of Health and the Ministry of Population Welfare through a joint memorandum of understanding aiming to forge functional integration, whereby the package of maternal, infant and child health services, including reproductive health and family planning, is comprehensively delivered by all facilities regardless of their managerial affiliation. This expressed unity of purpose has in turn encouraged provincial and district counterparts of the two ministries to scale up coverage and access to these essential services.

Delivering as One has converged the competencies and resource contributions of 14 UN agencies in support of the health and population joint programme, replacing the past legacy of little or no coordination. Moreover, the initiative has enabled the health and population joint programme to liaise with other joint programmes, attracting their support on key social determinants of health, thus expanding the gains accrued to this underfunded social sector. This exercise unveiled the potential for good that health and population joint programme has, when other joint programmes coherently undertake the implementation of multisectoral health protection and promotion interventions that include safe drinking water and sanitation, solid waste disposal, nutrition and food safety, environmental health, girls' education/female literacy and livelihood activities that collectively enable public policies to shape the social environment and prevent the underlying causes of ill health.

Mainstreaming the four identified cross-cutting issues of human rights, gender parity, civil society organizations 
and refugees posed a challenge, as it required the application of quantifiable tools to assess the level of strategic and operational integration of cross-cutting issues into the joint programmes and addressing existing gender disparities and inequalities [18]. The latter implied the application of direct and proxy measures to assess and monitor their societal implications. Appointing focal points on cross-cutting issues to undertake the necessary oversight and develop relevant advocacy and communication strategies for their effective implementation was another positive undertaking of the UN in Pakistan.

The Delivering as One initiative provided a road map for the sustainable implementation of joint programmes [6]. To scale up the progress of this evolving reform, $\mathrm{UN}$ agencies ought to recognize the government leadership role, adhere to the Paris Declaration of Aid Effectiveness and endorse wider partnerships as determined by the joint programmes' operational scope, and work with different government and nongovernmental organizations to advance the Delivering as One initiative $[4,5,8]$. The government and the UN need to realize that the reform process is not the end goal in itself, but rather a way to achieve the planned results $[5,8]$. Delivering as One delineated the four critical roles of the UN-being advisor to the government, convener of stakeholders, advocate for international standards and provider of technical support. Moreover, the evolving challenges for resource mobilization should not be allowed to hinder Delivering as One, as greater efforts need to be made, while the efficient use of available resources would provide greater leverage to the UN to expand the value of its resource outlay by achieving better results and reducing its transaction cost.

To promote horizontal collaboration within the UN system, intraagency Delivering as One processes need to be actively introduced, where the coherence envisaged at the country level is matched by direct engagement of the top executives at regional and headquarters levels in the Delivering as One process, and the different divisions and technical units of an organization persuaded to adopt an internal transformation process, committed to achieve organization-wide results. Country offices should be supported in pursuing the targets set for the different joint programmes, rather than considering the Delivering as One initiative as a function exclusively assigned to the UN field staff. The latter is even more critical for achieving unified business practices, why modest advances were made in this field. Likewise, the perception of some government sectors that the channelling of jointly mobilized resources through the UN will negatively affect government envisaged budgetary support needs to be mitigated. The latter is attained by directing the focus on the significance of the jointly programmed interventions, the challenging milestones to be attained, the financing predictability for sustained implementation and the management for results through joint monitoring and evaluation.

The Delivering as One experience in Pakistan offers the best opportunity for the UN to effectively engage in and support the national efforts geared to attain the Millennium Development Goals, rendering the fragmented status quo practices extinct. The health and population joint programme policy, strategic and programmatic support significantly outweighs the disjointed single agency interventions of the past. The programmatic strategies of this joint programme were streamlined in the 2010 national health policy; assisted and influenced the work of the Health System and Policy Unit of the Ministry of Health; catalysed public sector investment in several joint programme component domains; scaled up the joint programme components' implementation with significantimpact on maternal, neonatal, and child health, health promotion and nutrition, and the school health programme promoted the introduction of pictorial health warnings on cigarette packs; enhanced immunization services by training thousands of community-based Lady Health Workers on vaccination skills, accelerated poliomyelitis eradication efforts; and engaged parliament in policy dialogues on priority public health fields such as the control of tuberculosis, hepatitis viral infections and HIV/ AIDS. To further enhance the quality of joint programme components' implementation, UN participating agencies need to establish an interagency programme support teams at the operational level, closely liaising with their government counterparts and assisting the implementation processes of each of the different joint programme components.

The Delivering as One initiative also offers a framework of principles that guide the country-level operations of the UN development system and substantiate the legitimacy of advancing and guiding the nationally owned programmatic interventions. Special attention was also directed to the $\mathrm{Pa}$ kistan humanitarian crisis where the principles of Delivering as One were readily applied with great success. Pakistan took bold steps along with the UN for scaling up and consolidating Delivering as One and focused action on national priorities, acknowledging that there must be no going back to the fragmentation and unaffordable opportunity costs of the past. The health and population joint programme attracted the largest UN participation and enhanced agencies' relevance, coherence and comparative advantages in support of national health priorities and catalysed Delivering as One between government institutions, while seamlessly interrelating health with its social determinants, providing a value added to Delivering as One implementation. 


\section{Acknowledgement}

The authors wish to acknowledge the contribution of the UN Resident Coordinator/UN Country Teams for responding to the given questionnaire to assess their individual perceptions on the collectively gained experience on the Delivering as One UN reform process in Pakistan. The authors equally acknowledge the collaboration extended by the participating UN agencies in the health and population joint programme thematic working group and the support and leadership provided by the ministries of health and population and by their respective provincial health departments as well as the coordination offered by the Economic Affairs Division for the effective implementation of this initiative.

\section{References}

1. United Nations Resolution 55/2. United Nations millennium declaration. New York, United Nations, 2000 (http://www. un.org/millennium/declaration/ares552e.htm, accessed 2 July 2010).

2. Rome declaration on harmonization. Rome, Aid Harmonization \& Alignment, 2003 (http://www.aidharmonization.org/ ah-overview/secondary-pages/why-RomeDeclaration, accessed 2 July 2010).

3. Human development report 2003. Millennium development goals: a compact among the nations to end human poverty. New York, Oxford, Oxford University Press, 2003 (http://hdr.undp. org/en/media/hdr03_complete.pdf, accessed 2 July 2010). (Published for the United Nations Development Programme).

4. Paris declaration on aid effectiveness: ownership, harmonisation alignment, resultsandmutualaccountability. Paris, United Nations, 2005 (http://www.oecd.org/dataoecd/30/63/43911948.pdf, accessed 2 July 2010).

5. Report of the high-level panel on United Nations system-wide coherence in the areas of development, humanitarian assistance and the environment. New York, United Nations General Assembly, 2006 (http://www.undemocracy.com/A-61-583.pdf, accessed 2 July 2010) (A/61/583).

6. Delivering as one 2008 stocktaking synthesis report: joint reports by governments and UN country teams. New York, United Nations Development Group, 2008 (http://www.undg.org/ docs/10289/UNStocktakingSynthesisReportV6.pdf, accessed 2 July 2010).

7. Regional consultation on United Nations reform, health and development: a report. Colombo, Sri Lanka, 6-8 December 2007. New Delhi, Regional Office for South East Asia, World Health Organization, 2008 (SEA-UNR-01).

8. Delivering as one: one UN in Pakistan 2008-2010. Islamabad, United Nations, 2009.

9. Mid term review of medium term development framework 20052010. Islamabad, Pakistan, Planning Commission, 2008.

10. Poverty Reduction Strategy Paper (PRSP) 2. Islamabad, Pakistan, Finance Division, 2009.
11. Pakistan Millennium Development Goals Report 2006. Islamabad, Center for Research on Poverty Reduction and Income Distribution, Planning Commission, 2006 ) http://undp.org. pk/images/publications/MDG\%202006.pdf, accessed 2 July 2010).

12. Pakistan in the 21st century: Vision 2030. Islamabad, Pakistan, Planning Commission of Pakistan, 2007.

13. Country cooperation strategy for WHO and Pakistan 2005-2009. Cairo, World Health Organization, Regional Office for the Eastern Mediterranean, 2006.

14. Mohamud KB. A brief overview of health and social welfare development in the Eastern Mediterranean Region of WHO: the need for integrated community-based strategies. In Proceedings of third global symposium on health and welfare systems development in the 21st century. Kobe, Japan 6-8 November 2002. Kobe, WHO Kobe Centre, World Health Organization, 2002.

15. Consultation on WHO programme development and delivery at country level, including in context of UNDAF and other partnership platforms: Summary and way forward Hammamet, Tunisia, 8-10 2009. Geneva, World Health Organization, 2009 WHO/ DGR/CCO/09.04).

16. Hill T, Peter E. UN accountability issues and the role of NGOs and global civil society: a quick sketch. New York, UN Non-Government Liaison Service, 2007 (http://www.un-ngls.org/IMG/ pdf/UN_Accountability_paper_by_Hill_and_Peter_-_NGLS. pdf, accessed 2 July 2010).

17. General Assembly Resolution A/RES/62/208. Triennial comprehensive policy review of operational activities for development of the United Nations system. New York, United Nations, 2008 (http://www.unssc.org/web/programmes/LS/unep-unsscprecourse-material/GA\%20res\%20TCPR\%202007.pdf, accessed 2 July 2010).

18. Women and health: today's evidence, tomorrow's agenda. Geneva, World Health Organization, 2009 (http://whqlibdoc.who. int/publications/2009/9789241563857_eng.pdf, accessed 2 July 2010). 